\title{
A INFÂNCIA ESQUECIDA: UMA ANÁLISE DA OBRA CAPITÃES DA AREIA DE JORGE AMADO
}

\section{THE FORGOTTEN CHILDHOOD: AN ANALYZE OF THE WORK CAPTAINS OF THE SAND IN JORGE AMADO}

\author{
Recebido: 19/02/2020 | Aprovado: 19/05/2020 | Publicado: 10/07/2020 \\ DOI: https://doi.org/10.18817/rlj.v4i1.2268
}

\author{
Joselma Mendes ${ }^{1}$ \\ Orcid ID: https://orcid.org/0000-0003-3404-4629
}

\begin{abstract}
Resumo: O presente artigo aborda a temática do menor abandonado no romance "Capitães da Areia", de Jorge Amado que, de forma ousada e inovadora, não só assistiu às atrocidades da sociedade para com o menor, mas as denunciou através da sua arte, pois a obra é de cunho artístico, político e social. $\mathrm{O}$ autor relata os contrastes de uma época em que a sociedade e 0 governo de Salvador faziam descaso de suas crianças e as maltratavam em reformatórios. A referida obra, atualmente, é lida não apenas como registro social de uma época e de um lugar específico, mas como uma literatura que soube despertar a reflexão de um drama humano que ainda perdura: menores abandonados. Jorge Amado narra episódios intensos a respeito da vida de seus personagens, não só da vida triste, cheia de angústias dos menores por não terem uma família, sobretudo de suas conquistas, alegrias e amores. Nessa perspectiva, este trabalho apresenta o contexto histórico brasileiro da década de 30, época em que o romance foi escrito, destacando os principais acontecimentos políticos e sociais daquele período, realçando as características da literatura neorrealista, como instrumento de denúncia social, com o intuito de buscar o entendimento do que influenciou Jorge Amado.
\end{abstract}

Palavras-chave: Menor abandonado. Neorrealismo. Sociedade. Governo.

Abstract: This article deals with the theme of the abandoned child in the novel "Capitães da Areia", by Jorge Amado who, in a bold and innovative way, not only watched society's atrocities towards the minor, but denounced them through his art, because the work is artistic, political and social. The author reports the contrasts of a time when the society and the government of Salvador neglected their children and mistreated them in reformatories. This work is currently read not only as a social record of a specific time and place, but also as a literature that was able to awaken the reflection of a human drama that still lingers: abandoned minors. Jorge Amado narrates intense episodes about the life of his characters, not only the sad life, full of anguish of the minors for not having a family, but also of their conquests, joys and loves. In this perspective, this work presents the Brazilian historical context of the 1930s, a time when the novel was written, highlighting the main political and social events of that period, highlighting the characteristics of neorealistic literature, as an instrument of social denunciation, in order to seek the understanding of what influenced Jorge Amado.

Keywords: Abandoned children. Neorealism. Society. Government.

\footnotetext{
${ }^{1}$ Graduada em Letras pela Universidade Estadual do Maranhão - UEMA. Pós-graduada em Língua Portuguesa e Literatura pela Faculdade Evangélica do Meio Norte - FAEME (2015). Pósgraduada em Tutoria em Educação a Distância pela Universidade Cândido Mendes. Pós-graduada em Educação, Pobreza e Desigualdade Social pela Universidade Federal do Maranhão - UFMA. Professora de Língua Portuguesa da Rede Pública Estadual do MA. E-mail: joselma1000@hotmail.com
} 


\section{INTRODUÇÃO}

A leitura de obras literárias tem um papel relevante na formação do jovem acadêmico, porque através delas o leitor tem uma visão panorâmica das várias fases históricas, sociais e culturais do país, tem contato entre o mundo real e o ficcional; e por vezes mistura presente e passado, numa viagem imaginária numa inquietante busca por mais conhecimento.

A importância da literatura é inquestionável, mas se por um lado o contato com obras ainda é feito de maneira superficial ou obrigatória nas escolas e universidades, por outro, existe a desvalorização e/ou o desconhecimento de obras brasileiras, pautadas nos autores que divulgam o Brasil.

Em face à constatação, necessita-se da defesa de trabalhos de conclusão de cursos, de graduação ou Pós Graduação, voltados para a divulgação das obras de autores que retratam o Brasil de forma peculiar, com um olhar observador e ao mesmo tempo crítico, obras que contribuíram para a construção intelectual e que de alguma maneira colaboraram para a construção política e social do país. É nesse contexto que surgiu a pesquisa científica ora apresentada com o tema: A infância esquecida: Uma análise da obra Capitães da Areia do célebre autor Jorge Amado, homem que retratou sua época através de sua arte.

Essa escolha objetiva despertar o leitor para os problemas sociais abordados em obras literárias que ainda hoje são vigentes, em sua obra Jorge Amado "denuncia de maneira única e inovadora a problemática do menor abandonado e as consequências de criminalidade e discriminação". Duarte (1996, p.119).

Pertencente à segunda fase do Modernismo no Brasil, também conhecida como fase Neorrealista, "Capitães da Areia" constitui-se num romance de cunho político e social, que contextualiza a sociedade baiana de uma época em que o preconceito e as desigualdades sociais eram evidentes. A fase neorrealista, na qual está inserida a obra "Capitães da Areia" compreende os anos de 1930 a 1945, tratava-se de um momento, particularmente, tumultuado da sociedade brasileira, que contribuiu para o surgimento de uma série de modificações no plano social, político, econômico e especialmente literário no país, pois surgia 
uma nova forma de literatura, sensível às condições miseráveis das classes sociais, com livros diretamente vinculados ao debate político, ideológico dos anos 30 e 40.

Importantes escritores, como Jorge Amado, Graciliano Ramos, José Lins do Rego, Rachel de Queiroz, Érico Veríssimo, vão conduzir a narrativa literária a um novo realismo que objetiva mostrar fragmentos da realidade esquecida pelas narrativas oficiais. Obras que dialogam com seu tempo e se inserem na grande corrente da literatura social em vigor no período. Segundo Alfredo Bosi (2006, p.410) "As décadas de 30 e de 40 vieram ensinar muitas coisas úteis aos nossos intelectuais".

Pode-se dizer que esse foi o tempo em que, mais do que nunca, a produção intelectual se deixa marcar pela ideologia socialista: romances e poesias de combate, a narrativa se volta para o real e destaca as relações sociais desfavoráveis, objetivando construir uma literatura empenhada no processo de transformação da sociedade, conforme afirma Duarte $(1996$, p.19) ao relatar que: "No Brasil, em cuja História a literatura e a política andaram quase sempre de mãos dadas, este é o momento em que muitos escritores começam a querer dar as mãos aos operários".

Duarte (1996, p.30) ainda relata que surge "uma nova configuração de romance que se afigura no Brasil, o Romance Proletário que tem empenho realista e volta-se para a existência das multidões oprimidas". É nesse âmbito que nasce a literatura de denúncia social neorrealista, com textos preocupados em fazer do povo seu principal personagem, dando força à presença da classe trabalhadora na literatura brasileira que se firma de modo palpável no plano social e na luta pela conquista dos direitos trabalhistas.

Os autores que participaram da primeira fase continuam escrevendo, contudo, é a nova geração da década de 30, que consolida a renovação literária. Essa nova geração foi influenciada pelas ideias de Gilberto Freire, autor do Manifesto regionalista (1926), de Casa-Grande e Senzala (1933) e principal mentor do grupo regionalista do Recife. Já no campo da prosa, em que ocorre uma rica produção de romances, observa-se, segundo Tufano (2003) três tendências principais que caracterizam a forma de escrever de cada autor: 
a. Romance intimista e psicológico: em que predomina o interesse pela análise do mundo interior das personagens e seus conflitos íntimos. Em que se destacam os autores Lúcio Cardoso, Cornélio Pires e Ciro dos Anjos.

b. A segunda tendência é o romance de temática social urbana, em que predomina $o$ interesse pela análise dos conflitos que surgem entre as personagens e as estruturas sociais urbanas. Em que se destacam os autores: Érico Veríssimo, Dionélio Machado, marques Rebelo e Otavio de Faria.

c. A terceira diz respeito ao romance social nordestino, em que predomina a denúncia das injustiças sociais e dos problemas econômicos do nordeste, o drama dos retirantes da seca e a vida sofrida da população pobre. (TUFANO, 2003, p.39).

A publicação de A bagaceira, de José Américo de Almeida, em 1928, é o marco inicial dessa tendência, cujos autores principais são: Graciliano Ramos, José Lins do Rego, Raquel de Queiroz, Amando Fontes e Jorge Amado que em meio à repressão da ditadura Varga e crises sociais, seguiu firme, acreditando que suas obras pudessem influenciar a realidade do país. $O$ autor não poupava esforços para retratar em seus textos questões políticas e sociais do Brasil naquele momento, utilizando a Bahia de cenário e traçando os paradoxos dessa sociedade.

Declarou ter aprendido com o poeta romântico Castro Alves que, igual ao rifle, a metralhadora e ao punhal, a poesia é também arma do povo². Diante disso pode-se dizer que Jorge Amado trabalhou, com a arma da escrita, levando ao público problemas até então ignorados pela sociedade, temas comuns à Bahia de sua época e à atualidade em vários pontos do país.

Diante desse contexto, escolhemos a referida obra para ser trabalhada, de forma a enfatizar a temática do menor abandonado, não apenas como marginalizados, mas crianças normais cheias de sonhos, que mesmo sem pai, mãe e com sede de amor, têm o desejo recorrente e desesperante de pertencer a uma família e conquistar um lugar digno na sociedade.

\section{CAPITÃES DA AREIA}

Capitães da Areia é uma narrativa de cunho social, neorrealista, sexto livro escrito por Jorge amado ainda na sua primeira fase em que predomina 0

2In: SCHWARCZ, Caderno de Leituras 1999, p 17. 
gosto pelas questões políticas e sociais. Constitui-se em um romance urbano que de forma discreta e inovadora denunciou a vida dos meninos de rua e os maus tratos que tinham nos reformatórios, discorreu também sobre outros temas proibidos e modernos para época, como: o Comunismo, a intolerância, a religião afro-brasileira, a capoeira e o homossexualismo, denunciando o abuso do poder público quanto às estas questões.

Acontecimentos que fizeram a ditadura agir rapidamente para impedir sua publicação, censurado e perseguido, Capitães da Areia, que surge às vésperas da decretação do Estado Novo, em 10 de novembro de 1937, no período foram incinerados em praça pública, diversas obras de autores renomados, que eram consideradas subversivas por fazer apologia ao comunismo, incluindo 808 exemplares de Capitães da Areia como mostra a ata de incineração, presente no artigo "Leitura e Cidadania" de Assis Duarte (2004, p.40).

\title{
ATA DE INCINERAÇÃO
}

\begin{abstract}
Aos dezenove dias do mês de novembro de 1937, em frente à Escola de Aprendizes Marinheiros, nesta cidade do Salvador e em presença dos senhores membros da comissão de buscas e apreensões de livros, nomeada por ofício número seis, da então Comissão Executora do Estado de Guerra, [...] foram incinerados, por determinação verbal do Sr. coronel Antônio Fernandes Dantas, comandante da Sexta Região Militar, os livros apreendidos e julgados como simpatizantes do credo comunista, a saber: 808 exemplares de Capitães da areia.[...]

Transcrito do jornal Estado da Bahia, de 17-12-37.
\end{abstract}

Notadamente, a denúncia social feita por Jorge Amado, causou polêmica por evidenciar a questão da criança pobre e abandonada. $O$ autor tece uma crítica objetiva e detalhada, demonstrando que a sociedade é coadjuvante no que leva essas crianças ao crime e à marginalidade.

A história em questão revela o proletariado, a camada oprimida da sociedade, cujo destino de cada membro do grupo é mostrado, exemplificando a força, a resistência e a necessidade de união por questão de sobrevivência.

\subsection{Tempo e espaços percorridos na obra}


"Capitães da Areia" é composto de três partes, totalizando vinte e sete tópicos. A obra inicia e finaliza com reportagens publicadas no "Jornal da Tarde em Salvador", que para Hatoum (2009) "um recurso que acentua a verossimilhança da obra, dando ao leitor a impressão da verdade do que se narra". O romance possui uma linguagem simples e clara, caracterizada por um tom coloquial e popular aliados a um lirismo e crítica social, característica marcante da geração de 30 .

\begin{abstract}
Capitães da Areia. Eles furtavam, brigavam nas ruas, xingavam nomes, derrubavam negrinhas no areal, por vezes feriam com navalhas ou punhal homens e polícias. Mas, no entanto, eram bons, uns eram amigos dos outros. Se faziam tudo aquilo é que não tinham casa, nem pai, nem mãe, a vida deles era uma vida sem ter comida certa e dormindo num casarão quase sem teto. Se não fizessem tudo aquilo morreriam de fome, porque eram raras as casas que davam de comer a um, de vestir a outro. E nem toda a cidade poderia dar a todos. (AMADO, 2009, p. 106)
\end{abstract}

No que se refere ao tempo não há uma data específica no romance, senão a de 1937, data da sua publicação. No entanto, mesmo que o tempo não esteja explicitamente determinado na obra, é possível perceber que há uma contextualização com o mesmo período em que foi publicado, nos anos que seguiram ao Golpe de 30 e todas as agitações configuradas pelo mesmo na realidade brasileira, o que se nota através do percurso e das ações dos personagens.

Como exemplo de tempo encontrado na obra, através dos personagens, é a morte do pai de Pedro Bala, Raimundo, assassinado num confronto com policiais "... disse que era filho de um antigo grevista que foi morto num meeting na célebre greve das docas de 191..." (Amado, 2009, p. 193). Percebe-se que o tempo está impreciso. Outra referência temporal é a menção ao cangaceiro Lampião, que percorreu vários estados do Nordeste com seu bando nos anos 1920 e 1930.

$\mathrm{Na}$ obra há também alguns flashes de lembranças, que podem caracterizar um tempo psicológico, ainda que reduzido, em que o personagem João de Adão relembra a trajetória de vida do pai de Pedro Bala, o próprio Pedro Bala na cadeia pensa nos momentos vividos com sua Dora. No entanto, a narrativa segue linearmente, mostrando o início das aventuras dos Capitães da 
Areia, sua rotina de sobrevivência, o apogeu do grupo com a chegada de Dora e a partida de alguns membros mais velhos, que seguem diferentes caminhos.

Quanto ao espaço, a narrativa se passa na Bahia, na cidade de Salvador, considerada, pelos personagens, cidade alta, portuária, das docas, dos bondes, dos morros do samba, da macumba e da capoeira. O principal local de desenvolvimento do romance é na praia em torno do trapiche, espécie de armazém abandonado, local em que as crianças se abrigavam. Há também espaços secundários, como o sertão nordestino narrado na viagem de Volta Seca ao encontro do grupo de Lampião e as referências a llhéus, Aracaju e Rio de Janeiro esta última, na menção à exposição dos quadros do Professor.

\subsection{Personagens e suas ações}

Os personagens na obra podem ser denominados de "personagem coletivo, o que consiste num fenômeno criativo em que o narrador sujeito da enunciação traça o perfil de uma comunidade como um todo uníssono", (MOISES, p. 253, 2012) numa comunhão de ação, compartilhando vários sentimentos, entre eles o de tristeza e solidão no sentido de que não possuem uma estrutura familiar.

O grupo Capitães da Areia é composto por cerca de cem crianças com idades entre 8 e 16 anos, cada uma delas com histórias de vida peculiares, vivem em um trapiche abandonado no cais. Durante o dia, espalham-se subindo as ladeiras da cidade alta, donos de suas vidas com liberdade singular, conhecem cada ponto, beco e via desconhecidos para muitos, são donos da cidade. À noite retornam ao trapiche, barulhentos, deitados no tablado e em grande algazarra vão contando as aventuras do dia.

Cada personagem possui uma personalidade e um sonho diferente. A maioria deles, do sexo masculino, são designados por adjetivações presentes em apelidos calcados na aparência física ou nos dotes psicológicos.

Entre os capitães da areia existe um líder que comanda todas as decisões dos companheiros e os ajuda, para que não haja conflitos entre os mesmos. Seu nome é Pedro Bala que chega à liderança, quando consegue derrotar o mulato Raimundo, antes detentor da liderança, em uma luta, ficando com uma cicatriz no rosto. Pedro Bala é um jovem de aproximadamente 15 anos, loiro, forte, 
inteligente. Tornou-se menino de rua aos 5 anos de idade. Nunca soube de sua mãe e seu pai, conhecido como Loiro (Raimundo), morrera lutando pelos direitos dos doqueiros, liderando uma greve no porto, onde foi assassinado por policiais. Pedro é visto por todos do grupo como um bom líder, pois foi a partir da sua liderança que a fama dos Capitães da Areia espalhou-se por toda a Bahia, como mostra o trecho abaixo:

Todos reconheceram os direitos de Pedro Bala à chefia, e foi dessa época que a cidade começou a ouvir falar nos capitães da areia, crianças abandonadas que viviam do furto. Nunca ninguém soube 0 número exato de meninos que assim viviam. Eram bem uns cem, e desses mais de quarenta dormiam nas ruínas do velho trapiche. (AMADO, 2009, p. 27).

Apesar de não participar de todas as cenas da história, Pedro é linha condutora da narrativa, dando um caráter coesivo aos diversos quadros que são apresentados. Mantem ao longo da narrativa, o desejo de ser revolucionário e no final, torna-se líder sindical a exemplo do pai.

Pedro Bala olhou mais uma vez os homens que nas docas carregavam fardos para o navio holandês. Nas largas costas negras e mestiças brilhavam gotas de suor. Os pescoços musculosos iam curvados sob os fardos. E os guindastes rodavam ruidosamente. Um dia iria fazer uma greve como seu pai... Lutar pelo direito... Um dia um homem assim como João de Adão poderia contar a outros meninos na porta das docas a sua história, como contavam a de seu pai. Seus olhos tinham um intenso brilho na noite recém-chegada (AMADO, 2009. p. 88).

Jorge Amado retrata através de seus personagens diversas características comuns às crianças quando, por exemplo, expressa a bondade sem mágoas ou rancores através de João Grande, um menino de treze anos, aparentemente forte, mas que por dentro é bastante sentimental. É considerado bom, pelo fato de não se sentir bem em praticar as mesmas atitudes dos companheiros. Ingressou no grupo aos nove anos, desde que seu pai, um carroceiro, foi morto atropelado por um caminhão. Ele ficou perdido nas ruas e nunca mais voltou para casa, desde então vive com os seus amigos no velho trapiche. João Grande é outro personagem que tem êxito ao se tornar adulto, pois consegue sair da vida promíscua em que vivia e torna-se um marinheiro. 
Mostrando a coragem, obstinação e força do sertanejo Jorge Amado apresenta Volta Seca que tem um ódio incomum das autoridades e diz ser afilhado de Lampião. Chega ao trapiche depois que perde sua mãe na travessia do sertão. Apresenta uma obsessão pelo cangaço, desejava se tornar cangaceiro como seu padrinho, acompanhava todas as notícias do cangaço pelos jornais, lidas pelo Professor. No final da narrativa consegue se juntar ao grupo de Lampião, transformando-se em um cruel e temido cangaceiro. É capturado pela polícia e julgado.

O autor mostra a vida vadia e esperta dos malandros, de duas formas, Gato e Boa-Vida ambos malandros, porém bem diferentes um do outro, tanto no aspecto físico, como no modo de agir. Gato é o elegante, ágil e conquistador, costuma fazer falcatruas com o baralho, vive entre as prostitutas e se apaixona por uma delas, chamada Dalva. Já Boa-Vida que, segundo o autor, "não era dos que mais fazia pela vida. Gostava de deixar a vida correr, sem se preocupar muito... Comia na casa de um, ou de outro. Em geral não aborrecia a nenhum." (AMADO, 2009, p. 69) é malandro que gosta de estar nas rodas de samba, só rouba quando suas roupas rasgam no corpo de tão velhas, Boa-Vida vive uma vida boêmia, compondo e cantando samba nas rodas.

Como exímio defensor do direito à liberdade, inclusive religiosa, Jorge Amado não deixa despercebido o tema em suas obras, no caso de Capitães da Areia, tanto através de Pirulito, do Padre José Pedro ou a mãe de Santo Don' Aninha, o autor faz uma análise da perseguição ás manifestações religiosas de matriz africana e da relação de descaso da Igreja para com o menor na época.

Através de Pirulito o autor retrata uma criança carregada de ódio e rancor no coração, por sua miserável condição que a fé o resgata para uma nova trajetória de vida, baseada nos princípios divinos, "mas Deus chamava Pirulito. Nas noites do trapiche ouvia o chamado de Deus. Era uma voz poderosa dentro dele" (AMADO, 2009, p. 224). Assim, Pirulito tornou-se o único do grupo com vocação religiosa e evitava roubar, brigar na rua ou qualquer outra atividade comum aos Capitães da Areia por sua crença em Deus. No final da trama tornase frade, com ajuda do padre José Pedro.

Padre José Pedro que diferentemente dos padres da época, percebia que as crianças precisavam de ajuda, e principalmente de afeto. Sabia o quanto essas 
crianças abandonadas sofriam todos os dias para sobreviverem nas condições de abandono e descaso da sociedade e do governo, conforme o trecho a seguir: "o problema dos menores abandonados e delinquentes, que quase não preocupavam a ninguém em toda a cidade, era a maior preocupação do padre José Pedro" (AMADO, 2009, p. 72).

Como admirador da religião africana, arraigada na Bahia, o autor mais uma vez insere o referido tema em sua obra, nesse período, com a suspensão dos direitos em decorrência da Ditadura Militar, a liberdade de culto religioso foi cassada e os terreiros ficaram impedidos de funcionar, inclusive, 0 autor apresenta a resistência a tais impedimentos através da mãe de Santo Don" Aninha do terreiro da Cruz de Opô Afonjá, que vai até os Capitães para que estes peguem de volta a imagem de Ogum, arrancada de sua casa numa batida policial, ela reclama que “... - Não deixam os pobres viver... Não deixam nem o deus dos pobres em paz. Pobre não pode dançar, não pode cantar pra seu deus, não pode pedir uma graça a seu deus". (AMADO, 2009, p. 94).

Ainda entre os personagens principais de Capitães da Areia há uma menina chamada Dora, ela chega ao trapiche depois de ser encontrada nas ruas por Professor e João Grande, vagando com seu irmão Zé Fuinha de seis anos, o autor a descreve dizendo que "Dora tinha treze para quatorze anos, os seios já haviam começado a surgir sob o vestido parecia uma mulherzinha, muito séria"(AMADO, 2009, p. 163). Dora leva para o trapiche a presença feminina, presença esta, que faltava na vida dos Capitães, com carinho e atenção até então nunca recebido pelas crianças. Quando ganha a confiança do chefe, torna-se a primeira Capitã da Areia, tem grande influência nas atitudes e reflexões dos meninos, especialmente de Pedro Bala, com quem vive uma curta história de amor. É uma personagem essencial na construção da lógica do romance, pois é através dela que Pedro Bala e outros mudam a sua história de vida. No final da trama, morre ardendo em febre, após fugir do orfanato com a ajuda dos garotos. Mas antes, entrega-se para Pedro Bala, tornando-se sua esposa.

Todos aparentam ser fortes, contudo, o autor deixa claro em vários momentos a carência de afeto, amor, atenção, cuidados, pois vivem à mercê da sociedade e sentem a necessidade de ter alguém por perto para afagá-los e consolá-los, pois são crianças como qualquer outra. 
Querido-de-Deus era o personagem que ensinava os Capitães a sua arte advinda dos povos africanos (a capoeira), todos do trapiche o admiravam. E por último, não menos importante, um personagem de grande influência nas reflexões e decisões de Pedro Bala, o João de Adão que era um estivador negro e forte, antigo grevista, foi amigo do pai de Pedro Bala e companheiro nas greves.

Jorge Amado traça os caminhos de seus personagens, suas conquistas e desilusões, deixando uma mensagem ideológica aos leitores, como afirma Eduardo de Assis Duarte (1996) ao mencionar que:

O romance amadiano volta-se para a base do edifício social e joga luz sobre suas margens e desvãos, para ali descobrir/construir o humano. $O$ que se vê tensionado é o drama de seres a princípio incompletos, irrealizados enquanto cidadãos, mas que saem - ousam sair - para enfrentar a adversidade provinda de uma estrutura econômica, política e ideológica herdada do passado colonial. Mais que isto: seres que realizam nesse enfrentamento a sua formação como agentes sociais. (DUARTE, 1996, p. 114).

autor enfatiza que Jorge Amado coloca seus personagens incompletos e irrealizados enquanto cidadãos, mas que vão crescendo ideologicamente dentro da narrativa, tornando-se seres agentes sociais, que buscam mudar o meio no qual vivem.

\section{O MENOR ABANDONADO EM CAPITÃES DA AREIA}

Jorge Amado, corajosamente fez uma denúncia social ao escrever pela primeira vez em um romance, a situação do menor abandonado, abandono que em todos os capítulos, é enfatizado, seja por meio da reflexão dos garotos ou dos adultos que os cercam ou ainda pelos sutis comentários do autor.

Capitães da Areia. Eles furtavam, brigavam nas ruas, xingavam nomes, derrubavam negrinhas no areal, por vezes feriam com navalhas ou punhal homens e polícias. Mas, no entanto, eram bons, uns eram amigos dos outros. Se faziam tudo aquilo é que não tinham casa, nem pai, nem mãe, a vida deles era uma vida sem ter comida certa e dormindo num casarão quase sem teto. Se não fizessem tudo aquilo morreriam de fome, porque eram raras as casas que davam de comer a um, de vestir a outro. E nem toda a cidade poderia dar a todos (AMADO, 2009, p. 106). 
O menor, em Capitães de Areia, tem um papel de destaque ao falar das suas angústias, dificuldades e anseios, sendo colocado na condição de humano como qualquer outro, que mesmo sem oportunidades consegue acender e contribuir para uma nova realidade. O romance reflete a falta de perspectiva das crianças quanto a sua situação de abandonado, pois o mesmo acha que jamais sairá daquele mundo para uma vida próspera. "Professor baixou a cabeça: Deixa de ser besta, Bala. Tu bem sabe que do meio da gente só pode sair ladrão... Quem é que quer saber da gente? Quem? Só ladrão, só ladrão..." (AMADO, 2009, p. 138).

Com isso, percebe-se que mesmo o próprio indivíduo duvidando que pudesse ter um futuro diferente, com ajuda e incentivo necessários, este consegue ter outro destino. Como mostra um comentário na obra, de um observador ao ver o Professor pintando um quadro: “-Este menino promete. É pena que o governo não olhe essas vocações... - e lembravam casos de meninos da rua que, ajudados famílias, foram grandes poetas, cantores e pintores" (AMADO, 2009, p. 78). Fatores que Jorge Amado comprovou no decorrer da sua obra, pois todos que conseguiram mudar seu caminho tiveram ajuda de alguém. O que pode ser visto através dos personagens, Pedro Bala (herói- revolucionário), Pirulito (Frade), Professor (artista) e João Grande (marinheiro). Todos estes personagens, apesar da condição de exclusão em que viviam, conseguem seguir um caminho diferente de muitos dos Capitães da Areia, mudando sua história e percorrendo um caminho promissor e feliz.

Durante o romance, percebe-se ainda que o governo, que deveria zelar pela integridade física e de socialização dessas crianças, não cumpre o seu papel e as trata de forma desumana, Azevedo (2012) "adotando medidas de torturas como forma de levá-las a refletir seus atos e mudar”, o que as torna revoltadas, fazendo com que sejam dominadas por um ódio e uma revolta que as fazem sair cometendo os mesmos delitos ou até piores. Outra questão tocada no romance é o "descaso da sociedade que fecha os olhos para o problema das crianças abandonadas". (FREITAS, 1997).

Ao ler o romance, Capitães da Areia, é impossível não sentir piedade e ternura pelas crianças do trapiche, pois os menores abandonados são tratados 
como se não existissem, são criticados por um mundo completamente cheio de desigualdades.

O foco do romance "Capitães da Areia" é sem dúvidas o menor abandonado nas ruas da Bahia, crescendo exposto à marginalidade sem amor, esquecido pelo governo e ignorado pela sociedade. Um tema inédito até então, diferentemente de outros problemas sociais, como a seca, o preconceito racial, a fome e tantos outros, Jorge Amado inova ao falar da criança e seus dramas mais profundos, colocando-a como herói em uma época em que era vista como infratora e delinquente.

Para falar com propriedade sobre esse fenômeno, Jorge Amado conheceu bem o universo dos meninos de rua, como enfatiza Zélia Gattai Amado: "[...] Para escrever Capitães da Areia, Jorge Amado foi dormir no trapiche com os meninos. Isso ajuda a explicar a riqueza de detalhes, o olhar de dentro e a empatia que estão presentes na história" (GATTAI, apud AMADO, 2009, p. 263).

No caso do romance "Capitães da Areia", ao conter as formas mais complexas da infância esquecida, contribui para a construção de pensamentos sociais referentes aos menores abandonados no cenário brasileiro, pois "mergulhar em seu conteúdo colabora, portanto, para uma compreensão mais ampliada dos significados que têm sido atribuídos às crianças e aos adolescentes ao longo da história no Brasil”. (HATOUM, 2009).

\section{CONSIDERAÇÕES FINAIS}

Ora, como vimos, a literatura se constitui uma ferramenta de denúncia social, que ultrapassa épocas, influenciando nas mudanças da realidade, este trabalho traz em sua essência a luta de Jorge Amado ao expor um problema de cunho social, presente não só na Bahia, mas em todo o continente.

É preciso agradecer a fase neorrealista do Modernismo, por apresentar contribuições significativas, especialmente de Jorge Amado. O autor não poderia contribuir de outra forma, tratou de assuntos relevantes para sua época, em especial a questão do abandono das crianças e adolescentes entre 8 e 15 anos. Entretanto, não deixou de abordar assuntos como o homossexualismo, que para a época era estigmatizado pela sociedade; a varíola, uma doença que atingiu 
principalmente a população pobre que não tinha acesso à vacina; atacou a conivência da lgreja para com os desmandos com crianças abandonadas, porém não se esqueceu de colocar o Padre José Pedro como exceção.

Jorge Amado, com o romance "Capitães da Areia", permitiu-nos conhecer a sociedade daquela época, promovendo uma sensibilização para os problemas sociais, retratados não somente em seu tempo, mas evidenciado ainda na atualidade. Foi um escritor que viveu a sua época, com firmeza e sensibilidade, revelando intencionalmente a falta de compromisso daqueles que censuraram os negros, os pobres, os homossexuais e principalmente as crianças abandonadas.

O autor também enfatizou a repressão, a perseguição do regime militar de Getúlio Vargas, usou a escrita para denúncias, algumas vezes, de forma sucinta outros problemas sociais, enfatizando a força do homem em constantes lutas.

Cabe nesse momento, ressaltar a grande contribuição desse autor magnífico, que viveu o seu tempo, ilustrando que era preciso fazer algo para melhorar a vida do ser humano, especialmente porque somos levados à reflexão de que tais problemas continuam extremamente atuais.

Enfim, a referida obra trouxe meditações sobre situações contemporâneas, à medida em que se percebe, que em pleno século XXI, vários descasos do poder público e da sociedade ainda acontecem, o que nos estimula a desejar dias melhores, em meio a tantos desafios.

\section{Referências}

AMADO, Jorge. Capitães da Areia. São Paulo: Companhia das Letras, 2009.

BOSI, Alfredo. História concisa da literatura brasileira.34. ed.São Paulo: Cultrix, 1996.

DUARTE, Eduardo de Assis. Jorge Amado: romance em tempo de utopia. Rio de Janeiro: Record, 1996.

FREITAS, Marcos Cezar de. História social da infância no Brasil. São Paulo: Cortez, 1997.

HATOUM, Milton. Pós fácil: Capitães da Areia. São Paulo: Companhia das Letras, 2009.

MOISÉS, Massaud. A análise Literária. 18ªed. São Paulo: Cultrix, 2012. 
RUBIM, Rosane; CARNEIRO, Maried. Jorge Amado 80 anos de vida e obra: subsídios para pesquisa. Salvador: Fundação Casa de Jorge Amado, 1992.

TUFANO, Douglas. Modernismo: Literatura brasileira (1922-1945). São Paulo:Paulus, 2003.

SCHWARCZ, Lilia Moritz; GOLDSTEIN, IlanaSeltzer. Caderno de Leituras: a Literatura de Jorge Amado: Orientação para o trabalho em sala de aula. Companhia das Letras, 1998.Disponível em: www.jorgeamado.com.br. Acesso em: 10 out. 2012. 